\title{
Article \\ Genetic Approach to Elucidate the Role of Cyclophilin D in Traumatic Brain Injury Pathology
}

\author{
Ryan D. Readnower ${ }^{1,2,+}\left(\mathbb{D}\right.$, William Brad Hubbard ${ }^{1,2,3},+\mathbb{D}$, Olivia J. Kalimon ${ }^{1,2}$, James W. Geddes ${ }^{1,2}$ \\ and Patrick G. Sullivan 1,2,3,*iD
}

1 Spinal Cord and Brain Injury Research Center (SCoBIRC), University of Kentucky, Lexington, KY 40536, USA; ryan.readnower@gmail.com (R.D.R.); bradhubbard@uky.edu (W.B.H.); olivia.kalimon@uky.edu (O.J.K.); jgeddes@uky.edu (J.W.G.)

2 Department of Neuroscience, University of Kentucky, Lexington, KY 40508, USA

3 Lexington Veterans' Affairs Healthcare System, Lexington, KY 40502, USA

* Correspondence: patsullivan@uky.edu; Tel.: +1-859-323-4684

+ These authors contributed equally to this work.

Citation: Readnower, R.D.; Hubbard, W.B.; Kalimon, O.J.; Geddes, J.W.; Sullivan, P.G. Genetic Approach to Elucidate the Role of Cyclophilin D in Traumatic Brain Injury Pathology. Cells 2021, 10, 199. https://doi.org/ 10.3390/cells10020199

Academic Editors: Paolo Bernadi and Evgeny V. Pavlov

Received: 30 November 2020

Accepted: 15 January 2021

Published: 20 January 2021

Publisher's Note: MDPI stays neutral with regard to jurisdictional claims in published maps and institutional affiliations.

Copyright: (c) 2021 by the authors. Licensee MDPI, Basel, Switzerland. This article is an open access article distributed under the terms and conditions of the Creative Commons Attribution (CC BY) license (https:// creativecommons.org/licenses/by/ $4.0 /)$.

\begin{abstract}
Cyclophilin D (CypD) has been shown to play a critical role in mitochondrial permeability transition pore (mPTP) opening and the subsequent cell death cascade. Studies consistently demonstrate that mitochondrial dysfunction, including mitochondrial calcium overload and mPTP opening, is essential to the pathobiology of cell death after a traumatic brain injury (TBI). CypD inhibitors, such as cyclosporin A (CsA) or NIM811, administered following TBI, are neuroprotective and quell neurological deficits. However, some pharmacological inhibitors of CypD have multiple biological targets and, as such, do not directly implicate a role for CypD in arbitrating cell death after TBI. Here, we reviewed the current understanding of the role CypD plays in TBI pathobiology. Further, we directly assessed the role of $\mathrm{CypD}$ in mediating cell death following TBI by utilizing mice lacking the CypD encoding gene Ppif. Following controlled cortical impact (CCI), the genetic knockout of CypD protected acute mitochondrial bioenergetics at $6 \mathrm{~h}$ post-injury and reduced subacute cortical tissue and hippocampal cell loss at $18 \mathrm{~d}$ post-injury. The administration of CsA following experimental TBI in Ppif-/- mice improved cortical tissue sparing, highlighting the multiple cellular targets of CsA in the mitigation of TBI pathology. The loss of CypD appeared to desensitize the mitochondrial response to calcium burden induced by TBI; this maintenance of mitochondrial function underlies the observed neuroprotective effect of the CypD knockout. These studies highlight the importance of maintaining mitochondrial homeostasis after injury and validate $\mathrm{CypD}$ as a therapeutic target for TBI. Further, these results solidify the beneficial effects of CsA treatment following TBI.
\end{abstract}

Keywords: controlled cortical impact; mitochondrial bioenergetics; mitochondria; cyclosporin a; NIM811; mitochondrial permeability transition; Ppif; neuroprotection

\section{Introduction \\ 1.1. Secondary Mitochondrial Cascades in Traumatic Brain Injury}

Traumatic brain injury (TBI) is a major health concern that affects significant numbers of people worldwide. According to the Centers for Disease Control and Prevention (CDC), in the United States alone, there are an estimated 3 million TBI-related emergency department visits, hospitalizations, and deaths yearly [1]. There are no current approved treatments for TBI due to the complexity of the secondary injury cascade following primary head injury. One important player in this injury cascade is the mitochondrion. Known as the "powerhouse" of the cell, mitochondria are critical in regulating cellular energy homeostasis, redox balance, calcium buffering, and cell death [2]. In the secondary phase of brain injury, there is a bioenergetic collapse resulting from disrupted intracellular calcium homeostasis and increases in oxidative stress. Mitochondria sequester increased levels of 
intracellular calcium, concomitant with excitotoxic mechanisms after TBI. Once the mitochondria can no longer take up any more calcium, they become dysfunctional, generate ROS, and induce mitochondrial permeability transition (mPT).

\subsection{Role of $m P T$ in TBI Pathophysiology}

The mitochondrial permeability transition pore (mPTP) is a non-selective channel in the inner mitochondrial membrane, which leads to mitochondrial swelling and rupture of the outer mitochondrial membrane. In turn, an outer membrane rupture allows the release of calcium, cytochrome c, and other solutes $(<1.5 \mathrm{kDa})$ from the matrix into the cytosol. This results in mitochondrial swelling, dysfunction, rupture, and eventually cell death [3]. The release of cytochrome $\mathrm{c}$ through the pore into the cytosol activates downstream caspases, which also triggers apoptotic events, adding to CNS injury pathology, further implicates $\mathrm{mPT}$ as an important target for neuroprotection after TBI [4,5]. Since mitochondria are arbitrators of both apoptotic and necrotic cell death, they have become targets for therapeutic intervention in TBI and other neurodegenerative diseases [6]. Under stress conditions (such as high mitochondrial calcium or increased reactive oxygen species (ROS)), cyclophilin D (CypD) purportedly interacts with the adenine nucleotide translocase (ANT) and/or the F-ATP synthase of the inner mitochondrial membrane. The interaction with ANT results in a conformational change converts ANT into a non-specific pore located in the inner membrane. Following the voltage dependent anion channel (VDAC) interacts with the CypD/ANT complex, which promotes formation of the mPTP $[7,8]$. Other groups have confirmed the ability of ANT to form a large ion channel and constitute (or at least contribute) to $\mathrm{mPT}[9,10]$. However, recent evidence suggests that while these mitochondrial inner membrane proteins contribute to mitochondrial desensitization to high calcium levels, they may not constitute the primary mPTP [11,12]. After calcium overload, CypD can bind to the oligomycin sensitivity-conferring protein (OSCP) subunit of the ATP synthase and this interaction has been suggested to trigger the opening of a large conductance channel found in ATP synthase, which is potentially a major component of the mPTP [13-15]. Conversely, multiple groups have shown that MPTP can form in the absence of key subunits of the F-ATP synthase [16-18] and the assembled ATP synthase itself [19]; thus, the molecular identity of the mPTP remains highly disputed. Nevertheless, induction of mPT results in a loss of the mitochondrial membrane potential, resulting in the uncoupling of electron transport from ATP production. Moreover, mPT leads to mitochondrial swelling, rupture of the outer mitochondrial membrane, release of pro-apoptotic molecules (i.e., cytochrome c), and increased ROS production. Early studies found that CsA interacts and binds to CypD to inhibit mPT [20,21]; therefore, CypD has emerged as a therapeutic target in TBI.

\subsection{Therapeutic Targeting of $m P T$ by Cyclosporin $A$}

CypD, a target of the FDA approved immunosuppressant cyclosporin A (CsA), has been shown to play a key role in the modulation of mPTP formation $[7,22,23]$. CypD belongs to a family of proteins known as peptidyl-prolyl cis-trans isomerases (PPIases) and is localized in the mitochondrial matrix. This was elucidated by the observed effect of mPTP desensitization after CsA administration, requiring higher levels of intra-mitochondrial calcium to initiate pore formation [24]. The immunosuppressive properties of CsA were not shown to be the cause of neuroprotection after another study was performed with a more potent immunosuppressor, FK506. Both CsA and FK506 suppress T cell activation, but only CsA offered neuroprotection, most likely due to action on the MPTP [25]. There is an abundance of preclinical evidence that demonstrates that $\mathrm{mPT}$ inhibition following TBI is neuroprotective. Administration of CsA to inhibit mPT following TBI has proven to be effective at improving mitochondrial function and neuronal survival in multiple models of TBI [25-35]; however, there are contradictory results on the cognitive effects following TBI and CsA administration [27,36]. The neuroprotective effects of CsA are limited due to toxicity at high doses $[37,38]$ but Phase II trials involving $5 \mathrm{mg} / \mathrm{kg}$ of CsA have shown efficacy in TBI patients administered within $8 \mathrm{~h}$ post-injury [39]. Alternatively, in another 
Phase II study in severe TBI patients, administration of CsA after $12 \mathrm{~h}$ did not show any significant improvements in neurological outcomes [40]. In a rat model of spinal cord injury (SCI), the optimal dose and regimen of CsA determined by Sullivan et al., did not offer any beneficial effects in tissue sparing, which contradicted results obtained following TBI [33,41]. Among further investigation, it was found that isolated brain and spinal cord mitochondria are different; more specifically, in lipid peroxidation, mitochondrial mRNA count, complex-I activity, and calcium sequestration [42]. Spinal cord mitochondria were shown to form the MPTP at lower concentrations of calcium, with the addition of CsA offering only slight inhibition at doses used in TBI animal models. This is in stark contrast to cortical mitochondria, which require more calcium to form the pore and is significantly inhibited by CsA. One possible explanation for this difference is that there is more CypD mRNA in the spinal cord than in the cortex. In order for CsA to show neuroprotective effects in the SCI model, the optimal dose should be increased; however, due to its toxicity, this may not be a feasible therapeutic option [43]. Additionally, CsA has been shown to bind to other targets such as the T-cell activator, calcineurin, which makes pinpointing the mechanism(s) of action of CsA related to neuroprotection challenging [44].

\subsection{Therapeutic Targeting of $m P T$ by NIM811}

A non-immunosuppressive analog of CsA, N-methyl-4-isoleucine-cyclosporin (NIM811), has also been utilized to observe the effects of CypD inhibition on TBI outcomes. NIM811 is also tolerated better at high concentrations compared to CsA, most likely due to the substitution of isoleucine in place of leucine; this alternate prevents NIM811 from binding to calcineurin, the enzyme conferring CsA's immunosuppressive properties [45]. However, NIM811 binds CypD as well as CypA, another member of the cyclophilin, peptidylprolyl isomerase (PPI) family [46]. NIM811 improved motor function, improved mitochondrial function, decreased oxidative damage, and decreased neurodegeneration following TBI [47,48]. Results from these studies have shown NIM811 to have similar effects as CsA on preserving mitochondrial function after TBI. Our group has also determined that administration of a single dose of $10 \mathrm{mg} / \mathrm{kg}$ NIM811 is sufficient for improving mitochondrial respiration after experimental TBI [46]. In addition, dosing $15 \mathrm{~min}$ and $24 \mathrm{~h}$ after injury improved cortical tissue sparing and performance in the Morris water maze (MWM) test, implying translational efficacy of this compound after TBI [46]. NIM811 also improved outcome measures following SCI in rats albeit at higher doses [49-51]. Presumably, the neuroprotective actions of CsA and NIM811 are attributable to their inhibition of CypD, which prevents the binding of CypD to ANT and formation of the mPTP [52]. However, it is difficult to discern the protective mechanisms of NIM811 and CsA given that both have targets other than CypD. Further, as cell death may occur independent of CypD, direct evidence regarding the role of $\mathrm{CypD}$ in $\mathrm{mPTP}$ formation in the context of TBI is needed.

\subsection{The Effects of CypD Knockout (KO) in Neurodegenerative Diseases}

In order to examine the direct role of CypD in mPTP formation, CypD knockout mice lacking the encoding gene, Ppif, have been used by researchers. Studies have demonstrated the role CypD plays in $\mathrm{mPTP}$ formation and the subsequent effects on calcium uptake of mitochondria $[23,53]$. Interestingly, CypD-null mitochondria were not completely resistant to $\mathrm{mPTP}$ formation even though they were desensitized to calcium stress. Compared to brain mitochondria from WT mice, mitochondria from CypD KO mice retained 30-40\% more calcium when given in $10 \mu \mathrm{M}$ boluses. Additionally, CypD KO mitochondria required $80 \mu \mathrm{M}$ of calcium to diminish the membrane potential, whereas the wild-type mice only required $50 \mu \mathrm{M}$ calcium. Further, CsA treatment did not increase the calcium threshold in CypD KO mitochondria nor their ability to maintain membrane potential [54]. CypD knockout mice were indeed insensitive to CsA, providing further evidence of its action on CypD [53]. Studies in CypD knockout mice have demonstrated that mitochondria lacking CypD are resistant to $\mathrm{Ca}^{2+}$ - and ROS-induced $\mathrm{mPT}[23,53,54]$. In corroboration, the CypD knockout increased mitochondrial resistance to mPTP opening during cardiac 
ischemia/reperfusion (I/R) injury and lowers necrosis [22]. While the CypD knockout significantly reduces infarct area after cardiac I/R injury, which is predominantly driven by $\mathrm{Ca}^{2+}$ and oxidative stress, it did not protect against cell death induced by pro-apoptotic Bcl-2 family members [23]. CypD-mediated sensitization to mitochondrial calcium stress can also be observed in brain mitochondria, where the CypD knockout improved mitochondrial membrane polarization and survival due to desensitization to increased calcium levels $[54,55]$. This indicated that cell death may occur through either CypD-dependent or CypD-independent mechanisms but reinforced the close-knit relationship between CypD and mPTP opening.

To elucidate the role CypD plays in neuropathology following TBI, we subjected mice lacking the CypD encoding gene Ppif to controlled cortical impact (CCI). We hypothesize that genetic knockout of CypD would confer neuroprotection following TBI due to inhibition of mPT. Indeed, the CypD knockout restored acute mitochondrial function following TBI. In the subacute phase following injury, cortical tissue sparing and CA3 neuron density are improved in mice lacking $\mathrm{CypD}$, although this does not benefit cognitive function. The data demonstrate that knockout of $\mathrm{CypD}$, likely via maintenance of mitochondrial homeostasis, spares cortical tissue and protects CA3 neurons following TBI, which supports CypD as an important mediator of cell death following TBI.

\section{Materials and Methods}

\subsection{Animals and Experimental Design}

All of the studies performed were approved by the University of Kentucky Institutional Animal Care and Use Committee (IACUC). Additionally, the Division of Laboratory Animal Resources at the University is accredited by the Association for the Assessment and Accreditation for Laboratory Animal Care, International (AAALAC, International); all experiments were performed within its guidelines. All animal experiments complied with ARRIVE (Animal Research: Reporting of In Vivo Experiments) guidelines and experiments were carried out in accordance with the National Institutes of Health Guide for the Care and Use of Laboratory Animals (NIH Publications No. 8023, 8th edition, revised 2011). Ppif-null (CypD knockout (KO)) mice and control C57BL/6 wild-type mice were bred at the University of Kentucky (Lexington, KY, USA), and were originally obtained as a gift from Dr. J.D. Molkentin (Cincinnati Children's Research Foundation). Adult ( 8 to 10 weeks old) male wild-type (WT) and CypD KO mice were utilized and randomly assigned to experimental groups. The animals were housed 5 (mice) per cage and maintained in a 14-h light $/ 10 \mathrm{~h}$ dark cycle. All animals were fed a balanced diet ad libitum and water was reverse osmosis generated. One cohort was euthanized at $6 \mathrm{~h}$ post-injury for mitochondrial assessments ( $n=5-6$ /group) while a second cohort was euthanized at $18 \mathrm{~d}$ post-injury, following a week of rest and subsequent behavioral analysis, for tissue sparing and hippocampal cell count analysis ( $n=5$ /group). The final (third) cohort was administered treatment targeting $\mathrm{mPT}$ and was euthanized for tissue sparing assessment at $7 \mathrm{~d}$ postinjury ( $n=7-8$ /group). For mitochondrial bioenergetics assessment, experiments were conducted with $n=5-6$ biological replicates and for each biological replicate there were technical replicates of $n>3$. All data analysis was performed blinded to treatment groups.

\subsection{Controlled Cortical Impact}

Mice were subjected to a severe $(1.0 \mathrm{~mm})$ unilateral controlled cortical contusion TBI or sham-operation according to past studies [56-58]. Briefly, mice were put under anesthesia with $2-5 \%$ isoflurane and the skull was exposed through a midline incision. An approximately $3 \mathrm{~mm}$ craniotomy was made lateral to the midline and centered between bregma and lambda, without disrupting the dura. A cortical contusion was produced using a pneumatically driven injury device (TBI-0310 Impactor, Precision Systems and Instrumentation (PSI), Fairfax, VA USA) with a $2 \mathrm{~mm}$ tip as previously described [58]. Following injury, a prosthetic skull cap was glued over the craniotomy site and incisions 
were sutured together. Animals remained on a $37^{\circ}$ heating pad until they were mobile and fully responsive.

For the third cohort, mice subjected to a severe CCI were then administered vehicle (100\% DMSO), NIM811 (10 mg/kg), or CsA ( $20 \mathrm{mg} / \mathrm{kg}) 15 \mathrm{~min}$ after TBI with a subsequent injection at $24 \mathrm{~h}$ post-injury.

\subsection{Mitochondrial Isolation and Respirometry Analysis}

At $6 \mathrm{~h}$ post-injury, the first cohort of wild-type and CypD knockout mice were asphyxiated with $\mathrm{CO}_{2}$ until unconscious, decapitated, and the brains were rapidly removed and placed in isolation buffer ( $215 \mathrm{mM}$ mannitol, $75 \mathrm{mM}$ sucrose, 0.1\% BSA, $20 \mathrm{mM}$ HEPES, and $1 \mathrm{mM}$ EGTA; $\mathrm{pH}$ 7.2). The ipsilateral cortex was dissected with a $3 \mathrm{~mm}$-diameter punch centered on the site of impact. The cortical tissue punch contained tissue from the site of the impact and the surrounding penumbra. The tissue punches were homogenized and isolated by differential centrifugation as previously described $[56,59,60]$. Briefly, the homogenate was centrifuged at $1300 \times g$ for $3 \mathrm{~min}$. Following the first spin, the supernatant was placed in a fresh tube and the pellet was resuspended in isolation buffer and centrifuged at $1300 \times g$ for $3 \mathrm{~min}$. The supernatant from the first and second spins were collected in separate tubes and spun at $13,000 \times g$ for $10 \mathrm{~min}$. The pellets from both tubes were combined, resuspended in $400 \mu \mathrm{L}$ isolation buffer, and placed in a nitrogen bomb at $1200 \mathrm{psi}$ for $10 \mathrm{~min}$. The pressure in the nitrogen bomb was rapidly released and the sample was placed as the top layer on a Ficoll separation column, which consisted of a 10\% Ficoll layer and a 7.5\% Ficoll layer. The Ficoll column with sample was centrifuged at $100,000 \times g$ for $30 \mathrm{~min}$ at $4{ }^{\circ} \mathrm{C}$ using a Beckman SW 55Ti rotor and ultra-centrifuge.

The supernatants were carefully removed, and the pellet was resuspended in isolation buffer without EGTA and centrifuged at $13,000 \times g$ for $10 \mathrm{~min}$ at $4{ }^{\circ} \mathrm{C}$. In order to completely wash all Ficoll out of the sample, the mitochondrial pellets were recentrifuged at $10,000 \times g$ for $5 \mathrm{~min}$ at $4{ }^{\circ} \mathrm{C}$. The final mitochondrial pellet was resuspended in isolation buffer without EGTA to yield a concentration of $\sim 10 \mathrm{mg} / \mathrm{mL}$. The protein concentration was determined using a bicinchoninic acid protein assay kit (Pierce, Rockford, IL, USA).

Mitochondrial respiration was measured using a Seahorse Biosciences XFe24 Flux Analyzer (North Billerica, MA, USA) as previously described $[46,56,60]$. Briefly, $5 \mu \mathrm{g}$ of mitochondrial protein were added to each well in $50 \mu \mathrm{L}$ respiration buffer. The assay plates were centrifuged at $3000 \mathrm{rpm}$ for $4 \mathrm{~min}$ at $4{ }^{\circ} \mathrm{C}$. Additional respiration buffer was added to bring the starting volume to $475 \mu \mathrm{L}$. After calibration, the assay plate was placed and pyruvate/malate/ADP, oligomycin, FCCP, and rotenone/succinate were injected sequentially through ports A-D, respectively. The final concentrations of substrates and inhibitors were $5 \mathrm{mM}$ (pyruvate), $2.5 \mathrm{mM}$ (malate), $1 \mathrm{mM}$ (ADP), $1 \mu \mathrm{g} / \mathrm{mL}$ (oligomycin), $1 \mu \mathrm{M}$ (FCCP), $100 \mathrm{nM}$ (rotenone), and $10 \mathrm{mM}$ (succinate). Oxygen consumption rates (OCR) were recorded in each distinct respiration state.

\subsection{Morris Water Maze}

A variant of the MWM task was used to assess cognitive function/dysfunction following TBI in these experiments [61]. The maze was in low light and consisted of a circular pool filled with water $\left(27^{\circ} \mathrm{C}\right)$. A platform was placed below the water surface rendering it invisible and was used as the goal platform. The pool was situated in a room that had numerous extra-maze cues that remained constant throughout the experiment. A video camera system placed directly above the center of the pool recorded swimming performance and each video record was processed by a video motion analyzer (Ethovision-XT, Noldus, Leesburg, VA, USA). Water maze testing began $10 \mathrm{~d}$ after surgery and training consisted of four daily trials one each starting from a different labeled quadrant. Each trial was initiated by placing the mouse into the water in a quadrant either adjacent or opposite to the platform. The platform location was fixed throughout the training. Each trial lasted $60 \mathrm{~s}$ or until the mouse located the platform. Mice that did not find the platform were guided to it and given a latency score of $60 \mathrm{~s}$. Each mouse was required to spend $15 \mathrm{~s}$ 
on the platform at the end of each trial. During this learning period mice used external visual cues as a reference to find the submerged platform. The latency to find the platform was recorded for each trial. On the fifth day of the MWM task, mice were given one probe trial, in which the platform was removed. A first dependent measure was the time spent swimming in each quadrant. The second dependent measure was the number of times the mouse crossed over the platform arena.

\subsection{Tissue Processing and Tissue Sparing Measurement}

At 18 days post-injury, wild-type and CypD knockout mice were anesthetized by an overdose of pentobarbital ( $95 \mathrm{mg} / \mathrm{kg}$ body weight) and transcardially perfused with physiological saline followed by $4 \%$ paraformaldehyde. After removal, the brains were placed in $4 \%$ paraformaldehyde- $15 \%$ sucrose for an additional $24 \mathrm{~h}$. Coronal sections $(30 \mu \mathrm{m})$ were then cut using a freezing microtome, throughout the rostrocaudal extent of the brain, extending through the septal area to the most posterior extent of the hippocampus. A series of coronal tissue sections spaced $\sim 400 \mu \mathrm{m}$ apart (minimum of 12 slices) were mounted on slides, stained with cresyl violet, and subjected to image analysis for lesion volume assessment. Quantitative assessment of cortical damage employed a blinded unbiased tracing protocol utilizing the Cavalieri method of segmentation to compare ipsilateral cortex to contralateral cortex. All slides were assessed blindly with respect to treatment group, for ROI analysis to measure cortical sparing, using ImageJ software (NIH, Bethesda, MD, USA).

\subsection{Stereology-Hippocampal Cell Counts}

The same series of cresyl violet-stained coronal brain slices were used for hippocampal cell counting. All sampling was conducted using an Olympus BX51 microscope with a $60 \mathrm{X}$ oil objective, with an ASI automated stage (Eugene, OR, USA). The neuronal cells were distinguished from other cells based on the cell size, morphology and granular staining [62]. Bioquant Image analysis software ( $\mathrm{R}$ and M Biometrics, Memphis, TN, USA) was used to estimate the total cell number in ipsilateral hippocampal regions CA1, CA3, and DG using the optical fractionator method as previously described [63]. Briefly, this method involves sampling a known fraction of the section thickness, under a known fraction of the sectional area, in a known fraction of the sections that contain the structure. The total number of neurons (N) is estimated by: $N=\Sigma Q * t / h * 1 /$ asf $* 1 / \mathrm{ssf}$, where $\Sigma Q$ is the number of neurons counted in the optical dissectors, $t$ is the tissue thickness $(20 \mu \mathrm{m}), \mathrm{h}$ is the height of the dissector $(20 \mu \mathrm{m}), 1 /$ asf is the counting grid area $(100 \times 100) /$ the dissector area (CA3, CA 1-15 $\mu \mathrm{m} \times 15 \mu \mathrm{m}$; DG-10 $\mu \mathrm{m} \times 10 \mu \mathrm{m}$ ), and $1 / \mathrm{ssf}$ is the sampling section fraction (12).

\subsection{Statistics}

Power analysis was conducted (using $\mathrm{G}^{*}$ Power statistical software; version 3.0.10) for all experimental data. Analysis was completed based on the ANOVA or t-test. A priori analysis was performed and effect size was calculated based on expected mean $\pm \mathrm{SD}$ within each group. Power analysis was calculated for behavioral experiments using the following parameters: $\alpha=0.05,1-\beta=0.8$, and standard deviation $20 \%$ of mean (effect size $=1.12$ ) for experimental groups. For all statistical comparisons, significance was set at $p<0.05$. For each measure, data were measured using interval/ratio scales. The Brown-Forsythe and /or Bartlett's tests were performed to ensure homogeneity of variance. Furthermore, the Shapiro-Wilk test was completed to ensure normality. As these criteria were met for all experimental data, parametric statistics were employed for all analyses. Tissue sparing assessment with WT compared to CypD KO were analyzed using unpaired $t$-test. All other data were analyzed using one-way ANOVA followed by Tukey's post-hoc analysis. 


\section{Results}

\subsection{Cyclophilin D Knockout Improves Mitochondrial Bioenergetics}

We found that brain mitochondria derived from the CypD knockout buffered higher calcium levels compared to mitochondria from WT mice (data not shown), confirming previous research. To determine the effects of the CypD knockout on mitochondrial respiration following TBI, mitochondria were isolated at $6 \mathrm{~h}$ post-injury from the ipsilateral cortex of wild-type and CypD knockout mice. In the presence of pyruvate/malate/ADP, injury-induced impairments $\left(\mathrm{F}_{(2,14)}=8.37, p=0.003\right.$ WT Sham vs. WT Injured $)$ in complex I driven State III respiration (dependent on the rate of ATP synthase) were attenuated by the CypD knockout $\left(\mathrm{F}_{(2,14)}=8.37, p=0.047\right.$ WT Injured vs. CypD KO Injured) (Figure 1). There were no differences in State IV respiration (dependent upon proton leak across the inner membrane) among treatment groups. While complex II driven State $\mathrm{V}$ respiration (maximal rate of the electron transport chain) was significantly reduced in both WT Injured and CypD KO Injured mice $\left(\mathrm{F}_{(2,14)}=9.69, p<0.03\right)$, complex I driven State V respiration was only significantly reduced in WT Injured $\left(\mathrm{F}_{(2,14)}=5.08, p<0.03\right.$ WT Sham vs. WT Injured). The respiratory control ratio (RCR; a metric for the coupling of electron transport with ATP production) did not differ among groups, indicating a similar level of mitochondrial coupling between the groups (data not shown).

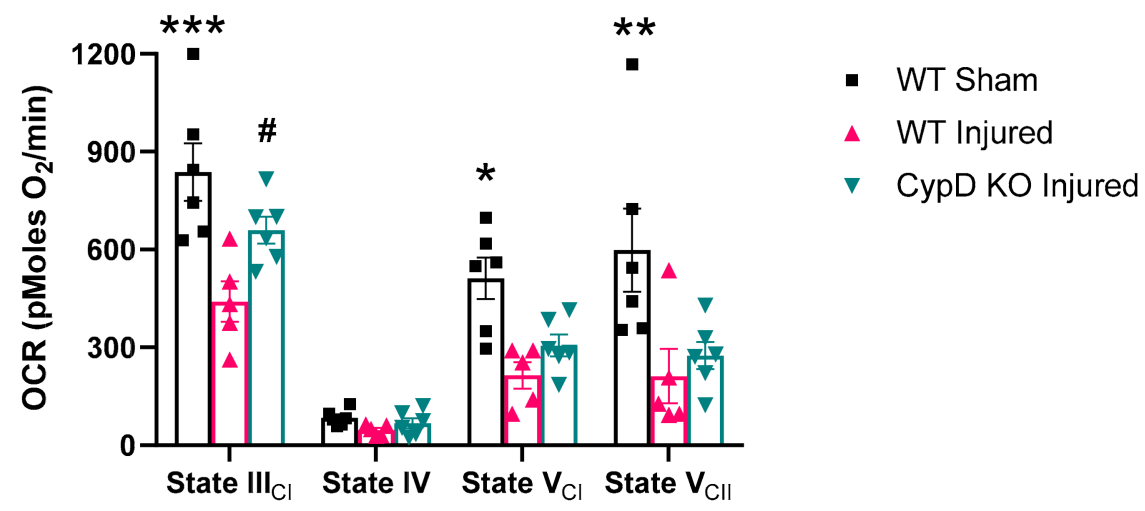

Figure 1. Cyclophilin D (CypD) knockout attenuates mitochondrial dysfunction following traumatic brain injury (TBI). At $6 \mathrm{~h}$ post-injury, complex I driven State III respiration was significantly reduced compared to sham in wild-type (WT) animals. However, CypD knockout attenuated State III mitochondrial dysfunction after TBI. For State V respiration, there was no significant difference between WT Injured and CypD KO Injured. ${ }^{*} p=0.0046$ vs. WT Injured, ${ }^{* *} p<0.002$ vs. WT Injured and knockout (KO) Injured, ${ }^{* * *} p=0.0001$ vs. WT Injured, ${ }^{*} p=0.047$ vs. WT Injured. Five $\mu \mathrm{g}$ mitochondrial protein were added to each well. Data points represent group mean \pm SEM. $N=5-6 /$ group.

\subsection{Cyclophilin D Knockout Alleviates TBI-Related Reduction of CA3 Hippocampal Neurons}

To determine the effects of CypD knockout on hippocampal cell survival after TBI, neurons were counted for regions dentate gyrus (DG), CA3, and CA1 using the optical dissector method. The number of surviving CA1, CA3, and DG neurons were estimated at 18 days post-injury (Figure 2). In WT mice, injury significantly decreased the number of neurons in ipsilateral CA1 $\left(\mathrm{F}_{(3,16)}=40.59 ; p<0.0001\right), \mathrm{CA} 3\left(\mathrm{~F}_{(3,16)}=9.31 ; p=0.003\right)$, and DG $\left(\mathrm{F}_{(3,16)}=37.02 ; p<0.0001\right)$ compared to WT Sham. In CypD KO mice, injury significantly decreased the number of neurons in ipsilateral CA1 $\left(\mathrm{F}_{(3,16)}=40.59 ; p<0.0001\right)$ and DG $\left(\mathrm{F}_{(3,16)}=37.02 ; p<0.0001\right)$ compared to CypD KO Sham. In ipsilateral CA3 of CypD KO Injured mice, neuronal count was not significantly different than CypD KO Sham mice, highlighting mitigation of the TBI-associated CA3 neuronal loss. 
A

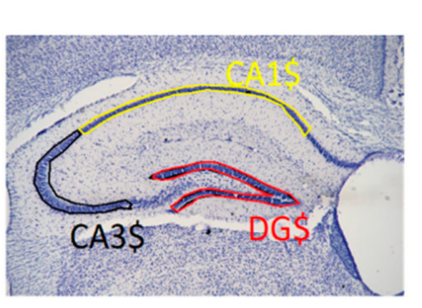

B

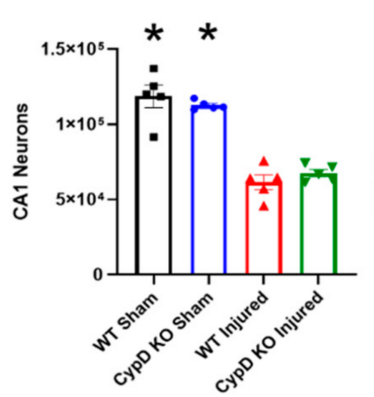

C

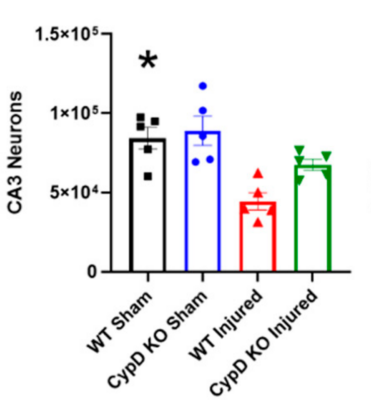

D

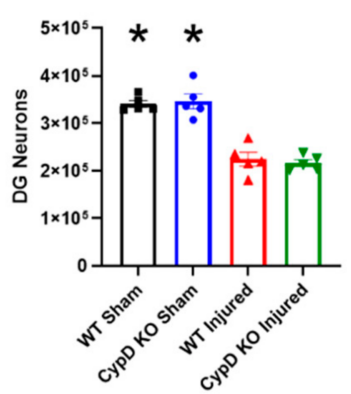

Figure 2. CypD knockout mitigates TBI-related CA3 neuronal loss. (A) Outline of hippocampal sub-regions, DG, CA3, and CA1. (B) Injury significantly decreased the number of CA1 neurons in both WT and CypD KO mice. (C) There was a significant decrease in CA3 neurons after TBI in WT mice. However, CypD knockout protected CA3 neurons from injury-induced cell loss. (D) TBI resulted in a significant decrease of DG neurons in both WT and CypD KO mice. ${ }^{*} p<0.003$ compared to injured counterpart in each genotype. Data points represent group mean $\pm \mathrm{SEM}$. $\mathrm{N}=5 /$ group.

\subsection{Cyclophilin D knockout Increases Tissue Sparing Following TBI}

In order to determine the effects of CypD knockout on tissue sparing following TBI, cortical tissue sparing was measured at 18 days following severe CCI utilizing the Cavalieri method. CypD KO Injured mice had significantly higher tissue sparing levels $(84.1 \pm 2.1)$ compared to WT Injured mice $(76.2 \pm 2.248)(t=2.57, p<0.03)$ (Figure 3$)$.

A

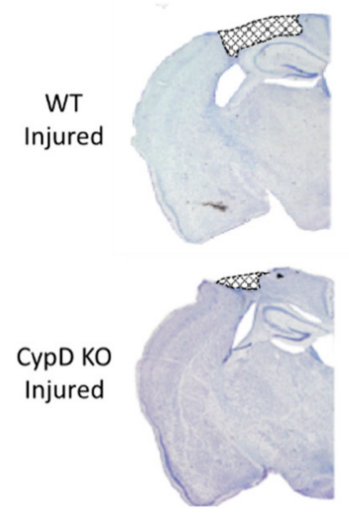

B

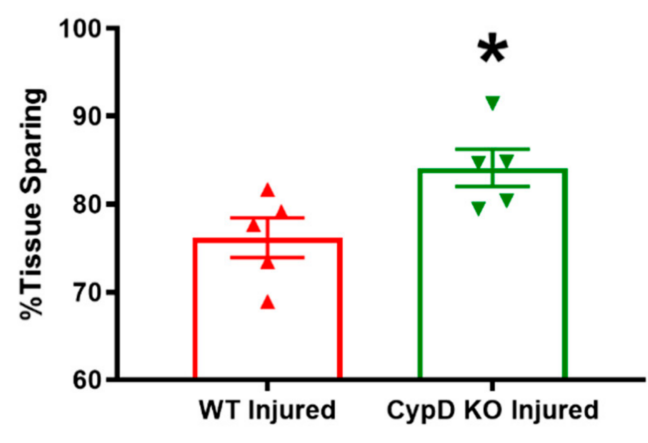

Figure 3. CypD knockout increases tissue sparing following TBI. (A) Representative coronal brain sections displaying lesion area (bregma level $-1.4 \mathrm{~mm}$ ). (B) Quantitative assessment of tissue sparing revealed that CypD knockout animals had significantly higher tissue sparing percentage compared to WT animals. ${ }^{*} p=0.033$. Data points represent group mean \pm SEM. $N=5$ /group.

\subsection{Cyclophilin D Knockout Does Not Improve Cognition Following TBI}

To examine the effect of CypD KO on cognitive function after TBI, mice performed the MWM task on five consecutive days starting at 10 days post-injury. In general, CypD $\mathrm{KO}$ mice (both Sham and Injured) displayed worse performance, higher latency to find the platform, during the learning phase (Figure $4 \mathrm{~A}$ ). This is highlighted by a significantly increased average latency over the four training days in the CypD KO Injured group compared to WT Injured animals (Figure $4 \mathrm{~B} ; \mathrm{F}_{(3,15)}=7.23, p=0.033$ ). During the probe trial, there was no difference in time in the target quadrant or platform quadrant crossings amongst experimental groups (Figure 4C,D). 
A

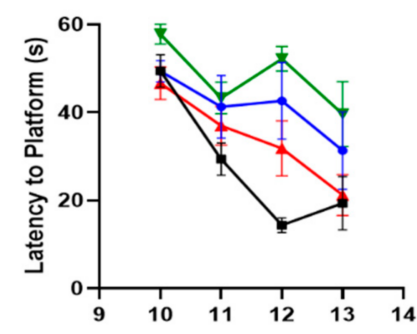

C

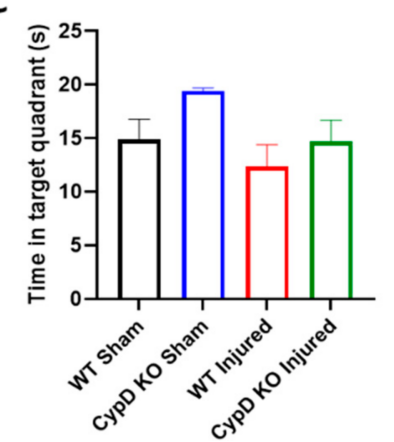

B
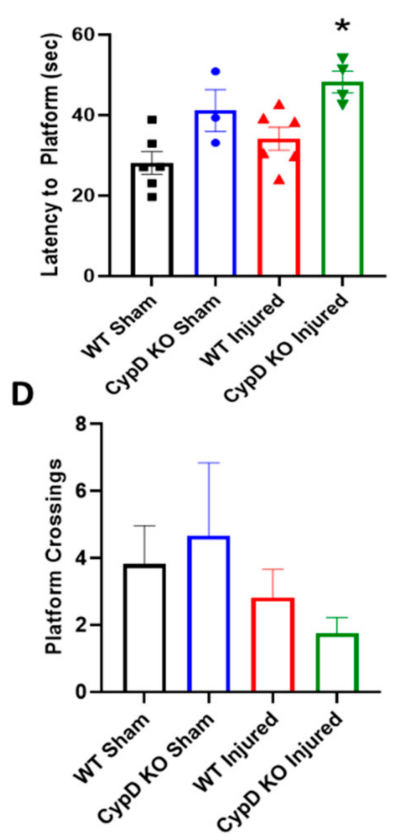

Figure 4. CypD knockout does not improve memory function following TBI. (A) Average learning progression, characterized by latency to platform, over days 10 to 13 after injury. (B) Morris water maze (MWM) latency to platform data collapsed across all training days. CypD knockout in injured animals resulted in an increase in latency to platform compared to WT Injured mice. ${ }^{*} p=0.033$ vs. WT Injured. (C) At $14 \mathrm{~d}$ after TBI, mice performed the probe trial. Time in the target quadrant was calculated. (D) During the probe trial, the number of times mice crossed the platform area was also quantified. Data points represent group mean \pm SEM. $N=3-6$ /group.

\subsection{Cyclosporin A Provides Neuroprotection in CypD KO Mice after TBI}

In order to determine the effects CsA and NIM811 administration in CypD KO mice after TBI, cortical tissue sparing was measured at 7 days following severe CCI utilizing the Cavalieri method. NIM811 administration after CCI in CypD KO mice did not improve tissue sparing compare to Vehicle administration (Figure 5). However, CsA treatment resulted in increased cortical sparing compared to vehicle-treated CypD KO mice $\left(\mathrm{F}_{(2,20)}=3.40\right.$, $p=0.039$ ).

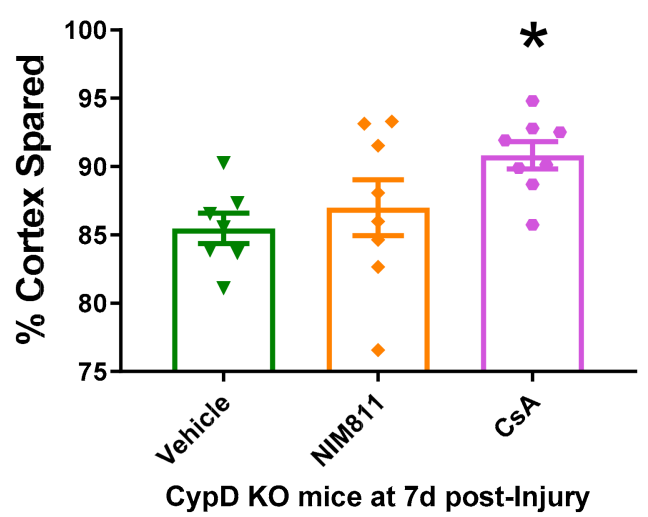

Figure 5. Cyclosporin A (CsA) and NIM811 treatment in CypD KO animals following TBI. While NIM811 did not alter tissue sparing in CypD KO animals compared to vehicle, CsA administration improved tissue sparing following experimental TBI mice. ${ }^{*} p=0.039$ vs. Vehicle. Data points represent group mean \pm SEM. $\mathrm{N}=7-8$ /group. 


\section{Discussion}

The results of this study uncovered the role of CypD in the pathophysiology of TBI, in which CypD-dependent cell death mechanisms have been implicated due to intracellular $\mathrm{Ca}^{2+}$ dyshomeostasis and subsequent mitochondrial calcium sequestration. We presented data that demonstrates that genetic ablation of $\mathrm{CypD}$ is neuroprotective following TBI. Further, CypD knockout attenuated injury-induced mitochondrial dysfunction. The data confirms the key role CypD plays in cell death following TBI.

Pharmacological studies have suggested an important role for CypD in neurodegeneration and TBI. Administration of CsA has been shown to be neuroprotective following multiple experimental models of TBI $[25,28,29,31,33,34]$. Since CsA has multiple biological targets, interacting with CypD and inhibiting calcineurin, the neuroprotective mechanism(s) of CsA is greatly debated. Indeed, we found that CsA provides neuroprotection via pathways other than CypD inhibition (Figure 5). NIM811, which inhibits CypD but does not affect calcineurin, has also been shown to have neuroprotective properties following TBI [46,47]. However, NIM811 has a U-dose response curve following TBI, which may indicate that NIM811 is acting through other potential off-target mechanisms, such as CypA. Genetic knockout of CypD provides a novel approach for directly examining the role that CypD plays without the confounding off-target effects of pharmacological studies.

The observed improvement in mitochondrial complex I activity following TBI in CypD knockout mice likely reflects a secondary effect of inhibition of MPTP formation via CypD ablation [48]. Improvement of mitochondrial complex I function suggests that loss of CypD increases mitochondrial preservation after TBI. These findings are in line with studies involving mitochondria isolated from CypD deficient mice, which showed that mitochondria lacking CypD are resistant to $\mathrm{Ca}^{2+}$ induced mPTP formation [23].

We found that the CypD knockout was neuroprotective at 18 days following TBI (Figures 2 and 3). While previous studies examined neuroprotection at 7 days postinjury $[33,35]$, we chose to examine neuroprotection at a later time point in order to incorporate cognitive assessment. The selective mitigation of CA3 neuronal loss observed in CypD knockout mice could be, in part, explained by the relative vulnerability of hippocampal subfields following brain contusion. Selective vulnerability of CA1 neurons is well-documented following hypoxia-ischemia insult [64,65]. In fact, it has been shown that inhibition of complex II with malonate results in a selective loss of CA1 neurons in rats [66]. However, another study showcases that CA3 is more vulnerable after CCI impact compared to CA1 [67]. Our group showed that mild mitochondrial uncoupling treatment lessens CA3 neuronal loss following severe CCI [56]. This suggests that CA3 neuronal loss may be selectively mediated through mitochondrial-dependent mechanisms and therefore more amenable to mitochondrial-directed therapy. CypD knockout reduced some, but not all, subtypes of axonal injury following mild TBI, again highlighting regional selectivity [68]. Further, the effects in CA3 may be partially explained by the predominant expression of CypD in GABAergic interneurons, including those of the CA3 [69]. It may also be pertinent to examine other brain regions in future studies as a report has demonstrated that $\mathrm{CypD}$ immunoreactivity is higher in the substantia nigra as compared to other regions such as cortex [69].

The CA3 region has been shown to play a critical role in spatial memory acquisition and in the formation of long-term spatial memory [70]. Since CypD knockout resulted in alleviation of CA3 neuronal loss, this suggests that modulation of CypD may improve memory following TBI. To directly address this, we performed cognitive studies using the MWM in CypD KO mice subjected to TBI. We did not observe any injury-induced impairment in cognitive function in WT animals using the MWM. Interestingly, we did observe a genotype-dependent impairment in MWM function in CypD KO mice compared to WT mice (Figure 4). Similar results were reported by Mouri and colleagues [71]. In these studies, genetic knockout of CypD resulted in cognitive impairments in several behavioral tasks. These data provide a potential physiological role for CypD, likely related to calcium 
signaling, and offer a mechanism by which memory is at least partially dependent on CypD function.

Although it is generally accepted that $\mathrm{mPT}$ plays a role in cell death, the mechanisms underlying induction of $\mathrm{mPT}$ following $\mathrm{TBI}$ remain unclear. There appears to be two alternative routes to cell death, one that is CypD dependent and an alternative route that is CypD independent; both pathways have been implicated in TBI. It is currently unclear on the amount of interplay between these two separate cell death pathways. There is growing evidence that suggests that $\mathrm{CypD}$ knockout is protective in neurodegenerative disorder models [72,73]. Interestingly, one study found that CypD-dependent cell death pathway is more critical in the progression of brain injury after hypoxic-ischemic insult [74]. This study further demonstrated that CypD knockout significantly reduced hypoxic-ischemic brain injury in adult mice while knockout exacerbated the injury in neonatal mice, highlighting age-dependent effects. Indeed, it has been shown that CypD levels in brain mitochondria increase with age, leading to dysfunction of F-ATP synthase [75]. Again, our results indicate that maintenance of mitochondrial homeostasis, by the absence of CypD, following TBI is protective.

We have previously demonstrated that continuous infusion of CsA for up to 7 days produces greater protection than a single dose administration of CsA following TBI [33]. Moreover, we have recently shown that the earlier the treatment with CsA is initiated following TBI the greater the neuroprotection that is afforded [35]. Taken together these results suggest that the mechanisms underlying cell death following TBI are an on-going process and that early intervention provides the greatest benefit. Past research demonstrated that NIM811 and CsA are equally as effective at providing neuroprotection in WT mice [47]. Here, we compared our own findings to these previously studies [33,35] by examining cortical tissue sparing also at 7 days post-injury. We show that CsA administration provides additive neuroprotection via non-CypD targeted biological pathway (Figure 5).

CypD knockout was shown to protect neurons against glutamate triggered cell death in vitro [55]. Importantly, the protection was dependent on the severity of the glutamate insult such that protection was not observed following the more severe insult. This may indicate that following more severe insults that $\mathrm{CypD}$ independent cell death mechanisms are more prevalent. In unpublished data from our lab, we showed that following a mild $(0.5 \mathrm{~mm})$ CCI TBI there is modest neuroprotection.

There are several limitations to this study. Only male mice were used to examine the effects of genetic knockout of CypD after TBI. Growing evidence suggests sex-specific responses to TBI [76]; therefore, future studies should examine sex in the context of CypDdependent cell death after experimental brain injury. Further, breeding of CypD KO animals posed a challenge, which resulted in low n/group for comparison to WT. Of course, it would be interesting to investigate the role of CypD in other models of experimental TBI, such as a mild closed head injury model [60]. Finally, the only cognitive task utilized was the MWM. We recognize that other cognitive assays, such as novel object recognition, could be more sensitive to deficits and future studies should incorporate additional assays to fully examine the role of CypD in TBI-induced cognitive dysfunction.

Although knockout of CypD leads to significant neuroprotection, we observed that this does not lead to cognitive restoration. In fact, $\mathrm{CypD} \mathrm{KO}$ animals display greater cognitive impairment. This could be explained by impaired calcium signaling in the absence of CypD or $\mathrm{mPT}$ as a necessary process to the recovery after TBI, whereby mitochondrial calcium scavenging and removal of dysfunction cells could result in overall neural network function. Nevertheless, our results suggest that CypD plays a prominent role in cell death mechanisms after TBI, as CypD ablation resulted in neuroprotection after TBI. This is the first study to report the effects of CypD knockout in a model of TBI and we showed that the lack of CypD significantly decreased neuronal damage associated with TBI. Thus, CypD-dependent cell death is critically involved in TBI, supporting the hypothesis that CypD is a valid target for neuroprotection following TBI. 
Author Contributions: Conceptualization, J.W.G. and P.G.S.; methodology, P.G.S.; formal analysis, R.D.R. and W.B.H.; investigation, R.D.R.; resources, J.W.G. and P.G.S.; writing-original draft preparation, R.D.R., W.B.H., and O.J.K.; writing-review and editing, W.B.H., O.J.K., J.W.G., and P.G.S.; visualization, W.B.H.; supervision, P.G.S.; funding acquisition, J.W.G. and P.G.S. All authors have read and agreed to the published version of the manuscript.

Funding: This research was funded by NIH/NINDS R01 NS062993 (JWG and PGS), NIH/NINDS P30NS051220 and funding from the Kentucky Spinal Cord and Head Injury Research Trust.

Institutional Review Board Statement: The study was conducted according to the guidelines of Association for the Assessment and Accreditation for Laboratory Animal Care, International and approved by the University of Kentucky Institutional Animal Care and Use Committee (protocol code 2009-0474, "Cyclophilin D as a Therapeutic Target following Traumatic Brain Injury" and date of approval (08/26/2013)). University of Kentucky Institutional Animal Care and Use Committee (IACUC). All animal experiments complied with ARRIVE (Animal Research: Reporting of In Vivo Experiments) guidelines and experiments were carried out in accordance with the National Institutes of Health Guide for the Care and Use of Laboratory Animals (NIH Publications No. 8023, 8th edition, revised 2011).

Informed Consent Statement: Not applicable.

Data Availability Statement: The data presented in this study are available on request from the corresponding author.

Acknowledgments: We would like to thank Andrea Sebastian and Leigha Arbic for expert technical assistance. Also, we would like to thank J.D. Molkentin (Cincinnati Children's Research Foundation) for providing the transgenic mice.

Conflicts of Interest: The authors declare no conflict of interest. The funders had no role in the design of the study; in the collection, analyses, or interpretation of data; in the writing of the manuscript, or in the decision to publish the results.

\section{References}

1. Centers for Disease Control and Prevention. TBI Data and Statistics. Available online: https://www.cdc.gov/traumaticbraininjury / data/ (accessed on 26 October 2020).

2. Yonutas, H.; Vekaria, H.; Sullivan, P.G. Mitochondrial specific therapeutic targets following brain injury. Brain Res. 2016, 1640, 77-93. [CrossRef] [PubMed]

3. Kulbe, J.R.; Hill, R.L.; Singh, I.N.; Wang, J.A.; Hall, E.D. Synaptic Mitochondria Sustain More Damage than Non-Synaptic Mitochondria after Traumatic Brain Injury and Are Protected by Cyclosporine A. J. Neurotrauma 2017, 34, 1291-1301. [CrossRef] [PubMed]

4. Springer, J.E.; Azbill, D.; Knapp, P.E. Activation of the caspase-3 apoptotic cascade in traumatic spinal cord injury. Nat. Med. 1999, 5, 943-946. [CrossRef] [PubMed]

5. Sullivan, P.G.; Keller, J.N.; Bussen, W.L.; Scheff, S.W. Cytochrome c release and caspase activation after traumatic brain injury. Brain Res. 2002, 949, 88-96. [CrossRef]

6. Hubbard, W.B.; Vekaria, H.J.; Sullivan, P.G. Chapter 17-Mitochondrial drug delivery systems: Therapeutic application for clinical bioenergetics in neurodegenerative disease. In Clinical Bioenergetics; Ostojic, S., Ed.; Academic Press: Cambridge, MA, USA, 2021; pp. 385-409. [CrossRef]

7. Crompton, M.; Virji, S.; Ward, J.M. Cyclophilin-D binds strongly to complexes of the voltage-dependent anion channel and the adenine nucleotide translocase to form the permeability transition pore. JBIC J. Biol. Inorg. Chem. 1998, 258, 729-735. [CrossRef]

8. Halestrap, A.P.; Davidson, A.M. Inhibition of Ca2+-induced large-amplitude swelling of liver and heart mitochondria by cyclosporin is probably caused by the inhibitor binding to mitochondrial-matrix peptidyl-prolyl cis-trans isomerase and preventing it interacting with the adenine nucleotide translocase. Biochem. J. 1990, 268, 153-160. [CrossRef]

9. Neginskaya, M.A.; Solesio, M.E.; Berezhnaya, E.V.; Amodeo, G.F.; Mnatsakanyan, N.; Jonas, E.A.; Pavlov, E.V. ATP Synthase C-Subunit-Deficient Mitochondria Have a Small Cyclosporine A-Sensitive Channel but Lack the Permeability Transition Pore. Cell Rep. 2019, 26, 11-17. [CrossRef]

10. Karch, J.M.; Bround, M.J.; Khalil, H.; Sargent, M.A.; Latchman, N.; Terada, N.; Peixoto, P.; Molkentin, J.D. Inhibition of mitochondrial permeability transition by deletion of the ANT family and CypD. Sci. Adv. 2019, 5, eaaw4597. [CrossRef]

11. Krauskopf, A.; Eriksson, O.; Craigen, W.J.; Forte, M.A.; Bernardi, P. Properties of the permeability transition in VDAC1-/-mitochondria. Biochim. Biophys. Acta Bioenerg. 2006, 1757, 590-595. [CrossRef]

12. Kokoszka, J.E.; Waymire, K.G.; Levy, S.E.; Sligh, J.E.; Cai, J.; Jones, D.P.; MacGregor, G.R.; Wallace, D.C. The ADP/ATP translocator is not essential for the mitochondrial permeability transition pore. Nat. Cell Biol. 2004, 427, 461-465. [CrossRef] 
13. Mnatsakanyan, N.; Llaguno, M.C.; Yang, Y.; Yan, Y.; Weber, J.; Sigworth, F.J.; Jonas, E.A. A mitochondrial megachannel resides in monomeric F1FO ATP synthase. Nat. Commun. 2019, 10, 1-11. [CrossRef] [PubMed]

14. Giorgio, V.; Bisetto, E.; Soriano, M.E.; Dabbeni-Sala, F.; Basso, E.; Petronilli, V.; Forte, M.A.; Bernardi, P.; Lippe, G. Cyclophilin D Modulates Mitochondrial F0F1-ATP Synthase by Interacting with the Lateral Stalk of the Complex. J. Biol. Chem. 2009, 284, 33982-33988. [CrossRef] [PubMed]

15. Urbani, A.; Giorgio, V.; Carrer, A.; Franchin, C.; Arrigoni, G.; Jiko, C.; Abe, K.; Maeda, S.; Shinzawa-Itoh, K.; Bogers, J.F.M.; et al. Purified F-ATP synthase forms a Ca2+-dependent high-conductance channel matching the mitochondrial permeability transition pore. Nat. Commun. 2019, 10, 1-11. [CrossRef] [PubMed]

16. He, J.; Carroll, J.; Ding, S.; Fearnley, I.M.; Walker, J.E. Permeability transition in human mitochondria persists in the absence of peripheral stalk subunits of ATP synthase. Proc. Natl. Acad. Sci. USA 2017, 114, 9086-9091. [CrossRef]

17. He, J.; Ford, H.C.; Carroll, J.; Ding, S.; Fearnley, I.M.; Walker, J.E. Persistence of the mitochondrial permeability transition in the absence of subunit c of human ATP synthase. Proc. Natl. Acad. Sci. USA 2017, 114, 3409-3414. [CrossRef]

18. Zhou, W.; Marinelli, F.; Nief, C.; Faraldo-Gómez, J.D. Atomistic simulations indicate the c-subunit ring of the F1Fo ATP synthase is not the mitochondrial permeability transition pore. eLife 2017, 6, 10580. [CrossRef]

19. Carroll, J.; He, J.; Ding, S.; Fearnley, I.M.; Walker, J.E. Persistence of the permeability transition pore in human mitochondria devoid of an assembled ATP synthase. Proc. Natl. Acad. Sci. USA 2019, 116, 12816-12821. [CrossRef]

20. Tanveer, A.; Virji, S.; Andreeva, L.; Totty, N.F.; Hsuan, J.J.; Ward, J.M.; Crompton, M. Involvement of Cyclophilin D in the Activation of A mitochondrial Pore by Ca2+ and Oxidant Stress. JBIC J. Biol. Inorg. Chem. 1996, 238, 166-172. [CrossRef]

21. Connern, C.P.; Halestrap, A.P. Purification and N-terminal sequencing of peptidyl-prolyl cis-trans-isomerase from rat liver mitochondrial matrix reveals the existence of a distinct mitochondrial cyclophilin. Biochem. J. 1992, 284, 381-385. [CrossRef]

22. Nakagawa, T.; Shimizu, S.; Watanabe, T.; Yamaguchi, O.; Otsu, K.; Yamagata, H.; Inohara, H.; Kubo, T.; Tsujimoto, Y. Cyclophilin D-dependent mitochondrial permeability transition regulates some necrotic but not apoptotic cell death. Nat. Cell Biol. 2005, 434, 652-658. [CrossRef]

23. Baines, C.P.; Kaiser, R.A.; Purcell, N.H.; Blair, N.S.; Osinska, H.; Hambleton, M.A.; Brunskill, E.W.; Sayen, M.R.; Gottlieb, R.A.; Ii, G.W.D.; et al. Loss of cyclophilin D reveals a critical role for mitochondrial permeability transition in cell death. Nat. Cell Biol. 2005, 434, 658-662. [CrossRef]

24. Fournier, N.; Ducet, G.; Crevat, A. Action of cyclosporine on mitochondrial calcium fluxes. J. Bioenerg. Biomembr. 1987, 19, 297-303. [CrossRef]

25. Scheff, S.W.; Sullivan, P.G.; Sullivan, S.W.S.G. Cyclosporin A Significantly Ameliorates Cortical Damage Following Experimental Traumatic Brain Injury in Rodents. J. Neurotrauma 1999, 16, 783-792. [CrossRef] [PubMed]

26. Albensi, B.C.; Sullivan, P.G.; Thompson, M.B.; Scheff, S.W.P.; Mattson, M.P. Cyclosporin Ameliorates Traumatic Brain-InjuryInduced Alterations of Hippocampal Synaptic Plasticity. Exp. Neurol. 2000, 162, 385-389. [CrossRef] [PubMed]

27. Alessandri, B.; Rice, A.C.; Levasseur, J.; de Ford, M.; Hamm, R.J.; Bullock, M.R. Cyclosporin A Improves Brain Tissue Oxygen Consumption and Learning/Memory Performance after Lateral Fluid Percussion Injury in Rats. J. Neurotrauma 2002, 19, 829-841. [CrossRef] [PubMed]

28. Büki, A.; Okonkwo, D.O.; Povlishock, J.T. Postinjury cyclosporin A administration limits axonal damage and disconnection in traumatic brain injury. J. Neurotrauma 1999, 16, 511-521. [CrossRef] [PubMed]

29. Okonkwo, D.O.; Büki, A.; Siman, R.; Povlishock, J.T. Cyclosporin A limits calcium-induced axonal damage following traumatic brain injury. NeuroReport 1999, 10, 353-358. [CrossRef] [PubMed]

30. Okonkwo, D.O.; Povlishock, J.T. An Intrathecal Bolus of Cyclosporin a before Injury Preserves Mitochondrial Integrity and Attenuates Axonal Disruption in Traumatic Brain Injury. Br. J. Pharmacol. 1999, 19, 443-451. [CrossRef] [PubMed]

31. Kilbaugh, T.J.; Bhandare, S.; Lorom, D.H.; Saraswati, M.; Robertson, C.L.; Margulies, S.S. Cyclosporin A Preserves Mitochondrial Function after Traumatic Brain Injury in the Immature Rat and Piglet. J. Neurotrauma 2011, 28, 763-774. [CrossRef] [PubMed]

32. Margulies, S.S.; Kilbaugh, T.; Sullivan, S.; Smith, C.; Propert, K.; Byro, M.; Saliga, K.; Costine, B.A.; Duhaime, A.-C. Establishing a Clinically Relevant Large Animal Model Platform for TBI Therapy Development: Using Cyclosporin A as a Case Study. Brain Pathol. 2015, 25, 289-303. [CrossRef]

33. Sullivan, P.G.; Thompson, M.; Scheff, S.W. Continuous Infusion of Cyclosporin a Postinjury Significantly Ameliorates Cortical Damage Following Traumatic Brain Injury. Exp. Neurol. 2000, 161, 631-637. [CrossRef] [PubMed]

34. Sullivan, P.G.; Thompson, M.B.; Scheff, S.W. Cyclosporin A Attenuates Acute Mitochondrial Dysfunction Following Traumatic Brain Injury. Exp. Neurol. 1999, 160, 226-234. [CrossRef] [PubMed]

35. Sullivan, P.G.; Sebastian, A.H.; Hall, E.D. Therapeutic Window Analysis of the Neuroprotective Effects of Cyclosporine A after Traumatic Brain Injury. J. Neurotrauma 2011, 28, 311-318. [CrossRef] [PubMed]

36. Riess, P.; Bareyre, F.M.; Saatman, K.; Cheney, J.; Lifshitz, J.; Raghupathi, R.; Grady, M.S.; Neugebauer, E.; McIntosh, T.K. Effects of chronic, post-injury Cyclosporin A administration on motor and sensorimotor function following severe, experimental traumatic brain injury. Restor. Neurol. Neurosci. 2001, 18, 1-8.

37. Berden, J.; Hoitsma, A.; Merx, J.; Keyser, A. Severe central-nervous-system toxicity associated with cyclosporin. Lancet 1985, 325, 219-220. [CrossRef]

38. de Groen, P.C.; Aksamit, A.J.; Rakela, J.; Forbes, G.S.; Krom, R.A.F. Central Nervous System Toxicity after Liver Transplantation. N. Engl. J. Med. 1987, 317, 861-866. [CrossRef] 
39. Hatton, J.; Rosbolt, B.; Empey, P.; Kryscio, R.; Young, B. Dosing and safety of cyclosporine in patients with severe brain injury. J. Neurosurg. 2008, 109, 699-707. [CrossRef]

40. Mazzeo, A.T.; Brophy, G.M.; Gilman, C.B.; Alves-Óscar, L.; Robles, J.R.; Hayes, R.L.; Povlishock, J.T.; Bullock, M.R. Safety and Tolerability of Cyclosporin A in Severe Traumatic Brain Injury Patients: Results from a Prospective Randomized Trial. J. Neurotrauma 2009, 26, 2195-2206. [CrossRef]

41. Rabchevsky, A.G.; Fugaccia, I.; Sullivan, P.G.; Scheff, S.W. Cyclosporin A Treatment Following Spinal Cord Injury to the Rat: Behavioral Effects and Stereological Assessment of Tissue Sparing. J. Neurotrauma 2001, 18, 513-522. [CrossRef]

42. Sullivan, P.G.; Rabchevsky, A.G.; Keller, J.N.; Lovell, M.; Sodhi, A.; Hart, R.P.; Scheff, S.W. Intrinsic differences in brain and spinal cord mitochondria: Implication for therapeutic interventions. J. Comp. Neurol. 2004, 474, 524-534. [CrossRef]

43. Sullivan, P.G.; Rabchevsky, A.; Waldmeier, P.; Springer, J. Mitochondrial permeability transition in CNS trauma: Cause or effect of neuronal cell death? J. Neurosci. Res. 2004, 79, 231-239. [CrossRef] [PubMed]

44. Waldmeier, P.C.; Zimmermann, K.; Qian, T.; Tintelnot-Blomley, M.; Lemasters, J.J. Cyclophilin D as a Drug Target. Curr. Med. Chem. 2003, 10, 1485-1506. [CrossRef] [PubMed]

45. Waldmeier, P.C.; Feldtrauer, J.-J.; Qian, T.; Lemasters, J.J. Inhibition of the mitochondrial permeability transition by the nonimmunosuppressive cyclosporin derivative NIM811. Mol. Pharmacol. 2002, 62, 22-29. [CrossRef] [PubMed]

46. Readnower, R.D.; Pandya, J.D.; McEwen, M.L.; Pauly, J.R.; Springer, J.E.; Sullivan, P.G. Post-Injury Administration of the Mitochondrial Permeability Transition Pore Inhibitor, NIM811, Is Neuroprotective and Improves Cognition after Traumatic Brain Injury in Rats. J. Neurotrauma 2011, 28, 1845-1853. [CrossRef]

47. Mbye, L.H.A.N.; Singh, I.N.; Carrico, K.M.; Saatman, K.E.; Hall, E.D. Comparative Neuroprotective Effects of Cyclosporin a and NIM811, a Nonimmunosuppressive Cyclosporin a Analog, following Traumatic Brain Injury. Br. J. Pharmacol. 2008, 29, 87-97. [CrossRef]

48. Mbye, L.; Singh, I.; Sullivan, P.; Springer, J.; Hall, E. Attenuation of acute mitochondrial dysfunction after traumatic brain injury in mice by NIM811, a non-immunosuppressive cyclosporin A analog. Exp. Neurol. 2008, 209, 243-253. [CrossRef]

49. Springer, J.E.; Visavadiya, N.P.; Sullivan, P.G.; Hall, E.D. Post-Injury Treatment with NIM811 Promotes Recovery of Function in Adult Female Rats after Spinal Cord Contusion: A Dose-Response Study. J. Neurotrauma 2018, 35, 492-499. [CrossRef]

50. McEwen, M.L.; Sullivan, P.G.; Springer, J.E. Pretreatment with the Cyclosporin Derivative, NIM811, Improves the Function of Synaptic Mitochondria following Spinal Cord Contusion in Rats. J. Neurotrauma 2007, 24, 613-624. [CrossRef]

51. Ravikumar, R.; McEwen, M.L.; Springer, J.E. Post-Treatment with the Cyclosporin Derivative, NIM811, Reduced Indices of Cell Death and Increased the Volume of Spared Tissue in the Acute Period following Spinal Cord Contusion. J. Neurotrauma 2007, 24, 1618-1630. [CrossRef]

52. Nicolli, A.; Basso, E.; Petronilli, V.; Wenger, R.M.; Bernardi, P. Interactions of Cyclophilin with the Mitochondrial Inner Membrane and Regulation of the Permeability Transition Pore, a Cyclosporin A-sensitive Channel. J. Biol. Chem. 1996, 271, 2185-2192. [CrossRef]

53. Basso, E.; Fante, L.; Fowlkes, J.; Petronilli, V.; Forte, M.A.; Bernardi, P. Properties of the Permeability Transition Pore in Mitochondria Devoid of Cyclophilin D. J. Biol. Chem. 2005, 280, 18558-18561. [CrossRef] [PubMed]

54. Gainutdinov, T.; Molkentin, J.D.; Siemen, D.; Ziemer, M.; Debska-Vielhaber, G.; Vielhaber, S.; Gizatullina, Z.; Orynbayeva, Z.; Gellerich, F.N. Knockout of cyclophilin D in Ppif-/ - mice increases stability of brain mitochondria against Ca2+ stress. Arch. Biochem. Biophys. 2015, 579, 40-46. [CrossRef] [PubMed]

55. Li, V.; Brustovetsky, T.; Brustovetsky, N. Role of cyclophilin D-dependent mitochondrial permeability transition in glutamateinduced calcium deregulation and excitotoxic neuronal death. Exp. Neurol. 2009, 218, 171-182. [CrossRef] [PubMed]

56. Hubbard, W.B.; Harwood, C.L.; Geisler, J.G.; Vekaria, H.J.; Sullivan, P.G. Mitochondrial uncoupling prodrug improves tissue sparing, cognitive outcome, and mitochondrial bioenergetics after traumatic brain injury in male mice. J. Neurosci. Res. 2018, 96, 1677-1688. [CrossRef] [PubMed]

57. Hall, E.D.; Bryant, Y.D.; Cho, W.; Sullivan, P.G. Evolution of post-traumatic neurodegeneration after controlled cortical impact traumatic brain injury in mice and rats as assessed by the de Olmos silver and fluorojade staining methods. J. Neurotrauma 2008, 25, 235-247. [CrossRef] [PubMed]

58. Yonutas, H.M.; Hubbard, W.B.; Pandya, J.D.; Vekaria, H.J.; Geldenhuys, W.J.; Sullivan, P.G. Bioenergetic restoration and neuroprotection after therapeutic targeting of mitoNEET: New mechanism of pioglitazone following traumatic brain injury. Exp. Neurol. 2020, 327, 113243. [CrossRef]

59. Hubbard, W.B.; Harwood, C.L.; Prajapati, P.; Springer, J.E.; Saatman, K.E.; Sullivan, P.G. Fractionated mitochondrial magnetic separation for isolation of synaptic mitochondria from brain tissue. Sci. Rep. 2019, 9, 1-13. [CrossRef]

60. Hubbard, W.B.; Joseph, B.; Spry, M.; Vekaria, H.J.; Saatman, K.E.; Sullivan, P.G.; Sulllivan, P.G. Acute Mitochondrial Impairment Underlies Prolonged Cellular Dysfunction after Repeated Mild Traumatic Brain Injuries. J. Neurotrauma 2019, 36, 1252-1263. [CrossRef]

61. Vekaria, H.J.; Hubbard, W.B.; Scholpa, N.E.; Spry, M.L.; Gooch, J.L.; Prince, S.J.; Schnellmann, R.G.; Sullivan, P.G. Formoterol, a $\beta 2$-adrenoreceptor agonist, induces mitochondrial biogenesis and promotes cognitive recovery after traumatic brain injury. Neurobiol. Dis. 2020, 140, 104866. [CrossRef]

62. Zhu, Y.; Liu, F.; Zou, X.; Torbey, M.T. Comparison of unbiased estimation of neuronal number in the rat hippocampus with different staining methods. J. Neurosci. Methods 2015, 254, 73-79. [CrossRef] 
63. Baldwin, S.A.; Gibson, T.; Callihan, C.T.; Sullivan, P.G.; Palmer, E.; Scheff, S.W. Neuronal Cell Loss in the CA3 Subfield of the Hippocampus Following Cortical Contusion Utilizing the Optical Disector Method for Cell Counting. J. Neurotrauma 1997, 14, 385-398. [CrossRef] [PubMed]

64. Kirino, T. Delayed neuronal death in the gerbil hippocampus following ischemia. Brain Res. 1982, 239, 57-69. [CrossRef]

65. Kirino, T.; Sano, K. Fine structural nature of delayed neuronal death following ischemia in the gerbil hippocampus. Acta Neuropathol. 1984, 62, 209-218. [CrossRef] [PubMed]

66. Davolio, C.; Greenamyre, J.T. Selective vulnerability of the CA1 region of hippocampus to the indirect excitotoxic effects of malonic acid. Neurosci. Lett. 1995, 192, 29-32. [CrossRef]

67. Mao, H.; Elkin, B.S.; Genthikatti, V.V.; Morrison, B.; Yang, K.H. Why Is CA3 More Vulnerable Than CA1 in Experimental Models of Controlled Cortical Impact-Induced Brain Injury? J. Neurotrauma 2013, 30, 1521-1530. [CrossRef]

68. Hånell, A.; Greer, J.E.; McGinn, M.J.; Povlishock, J.T. Traumatic brain injury-induced axonal phenotypes react differently to treatment. Acta Neuropathol. 2014, 129, 317-332. [CrossRef]

69. Hazelton, J.L.; Petrasheuskaya, M.; Fiskum, G.; Kristián, T. Cyclophilin D is expressed predominantly in mitochondria of $\gamma$-aminobutyric acidergic interneurons. J. Neurosci. Res. 2008, 87, 1250-1259. [CrossRef]

70. Florian, C.; Roullet, P. Hippocampal CA3-region is crucial for acquisition and memory consolidation in Morris water maze task in mice. Behav. Brain Res. 2004, 154, 365-374. [CrossRef]

71. Mouri, A.; Noda, Y.; Shimizu, S.; Tsujimoto, Y.; Nabeshima, T. The role of Cyclophilin D in learning and memory. Hippocampus 2009, 20, 293-304. [CrossRef]

72. Du, H.; Guo, L.; Fang, F.; Chen, D.; Sosunov, A.A.; McKhann, G.M.; Yan, Y.; Wang, C.; Zhang, H.; Molkentin, J.D.; et al. Cyclophilin $\mathrm{D}$ deficiency attenuates mitochondrial and neuronal perturbation and ameliorates learning and memory in Alzheimer's disease. Nat. Med. 2008, 14, 1097-1105. [CrossRef]

73. Du, H.; Guo, L.; Zhang, W.; Rydzewska, M.; Yan, S.S. Cyclophilin D deficiency improves mitochondrial function and learning/memory in aging Alzheimer disease mouse model. Neurobiol. Aging 2011, 32, 398-406. [CrossRef] [PubMed]

74. Wang, X.; Carlsson, Y.; Basso, E.; Zhu, C.; Rousset, C.I.; Rasola, A.; Johansson, B.R.; Blomgren, K.; Mallard, C.; Bernardi, P.; et al. Developmental Shift of Cyclophilin D Contribution to Hypoxic-Ischemic Brain Injury. J. Neurosci. 2009, 29, 2588-2596. [CrossRef] [PubMed]

75. Gauba, E.; Guo, L.; Du, H. Cyclophilin D Promotes Brain Mitochondrial F1FO ATP Synthase Dysfunction in Aging Mice. J. Alzheimer's Dis. 2016, 55, 1351-1362. [CrossRef] [PubMed]

76. Gupte, R.; Brooks, W.; Vukas, R.; Pierce, J.; Harris, J.L. Sex Differences in Traumatic Brain Injury: What We Know and What We Should Know. J. Neurotrauma 2019, 36, 3063-3091. [CrossRef] [PubMed] 